Faculty of Science

Faculty Publications

Ocean ventilation as a driver of interannual variability in atmospheric potential oxygen

Roberta C. Hamme \& Ralph F. Keeling

2008

(c) 2008 Roberta C. Hamme \& Ralph F. Keeling. This article is an open access article distributed under the terms and conditions of the Creative Commons Attribution (CC BY) license. http://creativecommons.org/licenses/by/4.0/

This article was originally published at:

https://doi.org/10.1111/j.1600-0889.2008.00376.x

Citation for this paper:

Hamme, R. C. \& Keeling, R. F. (2008). Ocean ventilation as a driver of interannual variability in atmospheric potential oxygen. Tellus B: Chemical and Physical Meteorology, 60(5), 706-717. https://doi.org/10.1111/j.1600-0889.2008.00376.x 


\section{Tellus B: Chemical and Physical Meteorology}

\section{Ocean ventilation as a driver of interannual variability in atmospheric potential oxygen}

\section{Roberta C. Hamme \& Ralph F. Keeling}

To cite this article: Roberta C. Hamme \& Ralph F. Keeling (2008) Ocean ventilation as a driver of interannual variability in atmospheric potential oxygen, Tellus B: Chemical and Physical Meteorology, 60:5, 706-717, DOI: 10.1111/j.1600-0889.2008.00376.x

To link to this article: https://doi.org/10.1111/j.1600-0889.2008.00376.x

$$
\begin{aligned}
& \text { (c) } 2008 \text { The Author(s). Published by Taylor \& } \\
& \text { Francis. }
\end{aligned}
$$

\section{曲 Published online: 18 Jan 2017.}

\section{Submit your article to this journal $₫$}

\section{Article views: 101}

\section{Q View related articles 두}

Citing articles: 18 View citing articles 


\title{
Ocean ventilation as a driver of interannual variability in atmospheric potential oxygen
}

\author{
By ROBERTA C. HAMME ${ }^{1 *}$ and RALPH F. KEELING ${ }^{2}, \quad{ }^{1}$ School of Earth and Ocean Sciences, \\ University of Victoria, Victoria, British Columbia, Canada; ${ }^{2}$ Scripps Institution of Oceanography, University of \\ California, San Diego, La Jolla, California, USA
}

(Manuscript received 20 February 2008; in final form 14 August 2008)

\begin{abstract}
We present observations of interannual variability on 2-5 yr timescales in atmospheric potential oxygen $\left(\mathrm{APO} \approx \mathrm{O}_{2}+\mathrm{CO}_{2}\right)$ from the Scripps Institution of Oceanography global flask sampling network. Interannual variations in the tracer APO are expected to arise from air-sea fluxes alone, because APO is insensitive to exchanges with the terrestrial biosphere. These interannual variations are shown to be regionally coherent and robust to analytical artefacts. We focus on explaining a feature dominant in records from the Northern Hemisphere stations, marked by increasing APO in the late 1990s, followed by an abrupt drawdown in 2000-2001. The timing of the drawdown matches a renewal of deep convection in the North Atlantic, followed the next year by a severe winter in the western North Pacific that may have allowed ventilation of denser isopycnals than usual. We find a weak correlation between changes in the interhemispheric APO difference and El Niño indices, and the observations show no strong features of the 1997-98 El Niño. Comparisons with estimates of variations in ocean productivity and ocean heat content demonstrate that these processes are secondary influences at these timescales. We conclude that the evidence points to variability in ocean ventilation as the main driver of interannual variability in APO.
\end{abstract}

\section{Introduction}

The Scripps Institution of Oceanography global flask sampling network has produced time-series records of the variation in atmospheric $\mathrm{O}_{2}$ concentrations, reported as $\mathrm{O}_{2} / \mathrm{N}_{2}$ ratios, at a growing number of sampling sites dating to the early 1990s. Atmospheric $\mathrm{O}_{2} / \mathrm{N}_{2}$ varies on a variety of timescales, including a long-term trend, strong seasonal cycles and interannual variations of 2-5 yr. The long-term trend in atmospheric $\mathrm{O}_{2} / \mathrm{N}_{2}$ and $\mathrm{CO}_{2}$ concentrations constrains the partitioning of the anthropogenic $\mathrm{CO}_{2}$ sink between ocean and terrestrial reservoirs (Manning and Keeling, 2006). Seasonal cycles have been used to evaluate models (Stephens et al., 1998; Battle et al., 2006) and to constrain the kinetics of air-sea gas exchange (Keeling et al., $1998 b$ ). Here, we combine measurements of atmospheric $\mathrm{O}_{2} / \mathrm{N}_{2}$ and $\mathrm{CO}_{2}$ to examine interannual variations and their potential causes due to air-sea gas fluxes. A companion paper, Rödenbeck et al. (2008), uses the Scripps flask network observations and an inversion of an atmospheric transport model to derive spatial information on interannual variability in air-sea fluxes.

\footnotetext{
*Corresponding author. e-mail: rhamme@uvic.ca DOI: $10.1111 / j .1600-0889.2008 .00376 . x$
}

Although far less important in decadal calculations, interannual variations in air-sea fluxes of $\mathrm{O}_{2}$ significantly impact estimates of the partitioning of $\mathrm{CO}_{2}$ sinks between ocean and land reservoirs on timescales of $5 \mathrm{yr}$ or less (McKinley et al., 2003; Bender et al., 2005; Nevison et al., 2008). Some features in the observations, such as an anomalously large change in the interhemispheric $\mathrm{O}_{2}$ difference in 1992, have been attributed to specific ocean flux events (Keeling et al., 1996). However, in general, the causes of observed interannual variations have received less attention, despite their potential to provide clues to the response of ocean biogeochemistry and physics to climate variability. Because the oceanic processes that affect $\mathrm{O}_{2} / \mathrm{N}_{2}$ also affect $\mathrm{CO}_{2}$, a greater understanding of the source of these atmospheric variations should help to improve the simulation of these processes in models. This should lead to better interpretation and prediction of observed variability in $\mathrm{CO}_{2}$ sinks, such as the unexpected variations in the ocean $\mathrm{CO}_{2}$ sink highlighted by recent studies (Schuster and Watson, 2006; Le Quéré et al., 2007).

Much of the interannual variability in atmospheric $\mathrm{CO}_{2}$ concentrations has been shown, based on $\delta^{13} \mathrm{C}$ measurements of $\mathrm{CO}_{2}$ (Keeling and Revelle, 1985; Keeling et al., 2005) and inversions of atmospheric $\mathrm{CO}_{2}$ (e.g. Rayner et al., 1999; Rödenbeck et al., 2003; Patra et al., 2005), to be caused by exchanges with the land biosphere driven by El Niño events. Terrestrially driven 
variability in $\mathrm{CO}_{2}$ also creates a mirrored variability in atmospheric $\mathrm{O}_{2}$ concentrations, because photosynthesis and respiration produce strongly correlated fluxes of $\mathrm{O}_{2}$ and $\mathrm{CO}_{2}$ with a molar ratio of approximately $-1.1 \mathrm{O}_{2}: 1 \mathrm{CO}_{2}$ (Severinghaus, 1995). However, as we will show, the record of interannual variability in $\mathrm{O}_{2} / \mathrm{N}_{2}$ also contains $2-3$ yr timescale events, with no counterpart in the $\mathrm{CO}_{2}$ record, such as a major decrease in atmospheric $\mathrm{O}_{2} / \mathrm{N}_{2}$ in $2000-01$.

We highlight the events that appear solely in the $\mathrm{O}_{2} / \mathrm{N}_{2}$ record using the tracer atmospheric potential oxygen (APO), a combination of atmospheric $\mathrm{O}_{2} / \mathrm{N}_{2}$ and $\mathrm{CO}_{2}$ measurements (Stephens et al., 1998; Keeling et al., 1998b).

$\delta \mathrm{APO}=\delta\left(\mathrm{O}_{2} / \mathrm{N}_{2}\right)+\frac{1.1}{0.2095}\left(\left[\mathrm{CO}_{2}\right]-350\right)$,

where $\left[\mathrm{CO}_{2}\right]$ is in units of $\mu \mathrm{mol} \mathrm{mol}{ }^{-1}, \delta \mathrm{APO}$ and $\delta\left(\mathrm{O}_{2} / \mathrm{N}_{2}\right)$ are in units of per meg, the factor 0.2095 is the atmospheric mole fraction of $\mathrm{O}_{2}$ and converts from units of $\mu \mathrm{mol} \mathrm{mol}^{-1}$ to per meg, 1.1 is the ratio of $\mathrm{O}_{2}$ production to $\mathrm{CO}_{2}$ consumption in terrestrial photosynthesis (Severinghaus, 1995), and 350 is an arbitrary reference $\mathrm{CO}_{2}$ concentration. The unit "per meg" is 0.001 per mil, a typical unit in stable isotope work. Atmospheric potential oxygen is largely unaffected by variations in terrestrial photosynthesis or respiration, because the fluxes of $\mathrm{O}_{2}$ and $\mathrm{CO}_{2}$ oppose each other in a ratio of 1.1. The effects of fossil-fuel combustion on APO are damped compared with $\mathrm{O}_{2}$ or $\mathrm{CO}_{2}$ but not eliminated, because combustion ratios for fossil fuels are higher than $-1.1: 1$, particularly for petroleum and natural gas (Keeling, 1988). From 1991 to 2004, the standard deviation of the yearly loss in APO due to fossil-fuel burning and cement manufacture, after subtraction of the linear trend, was only 0.06 per meg $\mathrm{yr}^{-1}$ (Marland et al., 2007). As we will show, the observed interannual variability in APO can be a hundred times greater than this.

The annual-mean spatial gradient in APO has been used as a validation test of the air-sea $\mathrm{O}_{2}$ and $\mathrm{CO}_{2}$ fluxes generated by global ocean carbon models (Stephens et al., 1998; Gruber et al., 2001; Battle et al., 2006; Naegler et al., 2007). Observations generally show an equatorial maximum in APO that falls off towards higher latitudes. Stephens et al. (1998) and Gruber et al. (2001) found that the model-generated ocean fluxes combined with an atmospheric transport model were unable to closely simulate the interhemispheric gradient in APO. However, later attempts show better agreement, which may be attributable both to model improvements and to changes in the observed gradients. Battle et al. (2006) show that the latitudinal APO gradient has varied significantly with time and that it may be sensitive to the choice of sampling stations or networks used in constructing the gradient. Besides annual mean patterns, there are also known deficiencies in the representation of variability in some models. In a companion paper, Rödenbeck et al. (2008) show that the OPA-PISCES-T model, a state-of-the-art combined ocean circulation and biogeochemistry model (Le Quéré et al., 2007), underestimates the interannual variability in air-sea APO fluxes by a factor of two or more, a deficiency likely shared by other existing models. Understanding the source of these interannual variations in APO is essential to using this tracer to validate and improve ocean and atmospheric models (Naegler et al., 2007).

In this paper, we show that APO exhibits patterns of variability that are coherent between stations in the Scripps network and must result from large-scale changes in atmospheric concentrations. Comparison to APO data from other networks is outside the scope of this study. We explore potential causes of these interannual variations due to variability in wintertime ventilation of subsurface waters, in ocean productivity and in ocean heat content. We conclude that variability in ventilation rates is the most likely driver of the largest variations observed so far in the APO record.

\section{Methods}

Flasks of atmospheric air are collected approximately every two weeks at nine sampling stations that span the globe in a meridional transect (Fig. 1). Station locations were selected to minimize the influence of local land biota and fossil-fuel burning. Appropriate sampling conditions are determined based on local wind direction, wind speed, and, where available, additional chemical tracer concentrations. Flasks are typically collected in triplicate and results for all flasks collected on a given date averaged to compute a daily mean. We exclude data from Mauna Loa and the South Pole before mid-1998, because these early data were adversely impacted by fractionation during sampling (Manning, 2001). Sampling at Niwot Ridge and MacQuarie Island occurred during only $2 \mathrm{yr}$ in the early 1990s, so we have excluded these stations from our interannual analysis.

At Scripps, air samples are analysed for $\mathrm{O}_{2} / \mathrm{N}_{2}$ using an interferometric technique and for $\mathrm{CO}_{2}$ by a non-dispersive infrared analyser (Keeling et al., 1998a). The $\mathrm{O}_{2} / \mathrm{N}_{2}$ ratio is expressed as the relative deviation from a reference ratio according to

$\delta\left(\mathrm{O}_{2} / \mathrm{N}_{2}\right)=\left[\left(\mathrm{O}_{2} / \mathrm{N}_{2}\right)_{\text {sample }} /\left(\mathrm{O}_{2} / \mathrm{N}_{2}\right)_{\text {reference }}-1\right]$,

where the resulting delta value is multiplied by $10^{6}$ and expressed in "per meg" units. The $\mathrm{O}_{2} / \mathrm{N}_{2}$ reference is derived from a suite

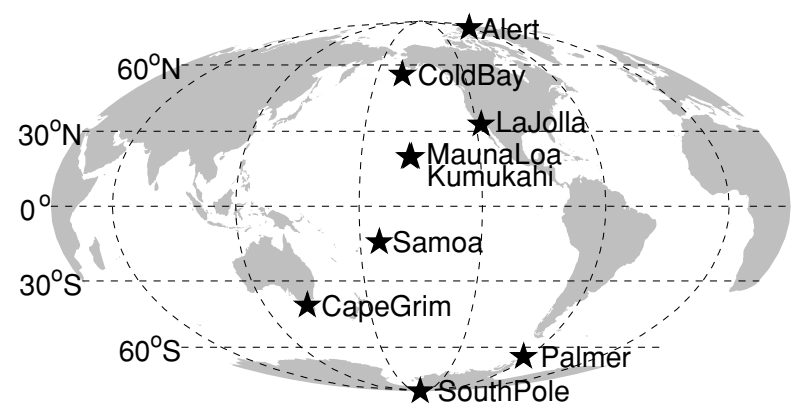

Fig. 1. Location map of stations in the Scripps flask sampling network. 
Table 1. Locations, elevations and number of months with missing data in the time series of each sampling site in the Scripps flask sampling network. Weightings used in constructing the global mean APO are listed for different station combinations. Weightings for individual hemispheres were scaled to bring the total weighting to one for that hemisphere.

\begin{tabular}{|c|c|c|c|c|c|c|c|}
\hline \multirow[b]{2}{*}{ Station name } & \multirow[b]{2}{*}{$\begin{array}{l}\text { Latitude } \\
\left({ }^{\circ}\right)\end{array}$} & \multirow[b]{2}{*}{$\begin{array}{c}\text { Longitude } \\
\left({ }^{\circ}\right)\end{array}$} & \multirow[b]{2}{*}{$\begin{array}{c}\text { Elevation } \\
\text { (m asl) }\end{array}$} & \multirow{2}{*}{$\begin{array}{c}\text { Months } \\
\text { missing } \\
\text { data }\end{array}$} & \multicolumn{3}{|c|}{ Global station weightings } \\
\hline & & & & & $\begin{array}{c}7 \mathrm{stn} \\
1996.7 \text {-present }\end{array}$ & $\begin{array}{c}5 \mathrm{stn} \\
1993.4-1996.7\end{array}$ & $\begin{array}{c}3 \mathrm{stn} \\
1991.25-1994.3\end{array}$ \\
\hline Alert & $82.5 \mathrm{~N}$ & $62.3 \mathrm{~W}$ & 210 & 2 & 0.05 & 0.12 & 0.25 \\
\hline Cold Bay & $55.2 \mathrm{~N}$ & $162.7 \mathrm{~W}$ & 25 & 2 & 0.11 & & \\
\hline La Jolla & $32.9 \mathrm{~N}$ & $277.3 \mathrm{~W}$ & 15 & 15 & 0.12 & 0.16 & 0.25 \\
\hline Mauna Loa & $19.5 \mathrm{~N}$ & $155.6 \mathrm{~W}$ & 3397 & 2 & & & \\
\hline Kumukahi & $19.5 \mathrm{~N}$ & $154.8 \mathrm{~W}$ & 40 & 4 & 0.2 & 0.20 & \\
\hline Samoa & $14.2 \mathrm{~S}$ & $170.6 \mathrm{~W}$ & 42 & 0 & 0.24 & 0.24 & \\
\hline Cape Grim & $40.7 \mathrm{~S}$ & $144.7 \mathrm{E}$ & 94 & 3 & 0.17 & 0.28 & 0.50 \\
\hline Palmer & $64.7 \mathrm{~S}$ & $64.0 \mathrm{~W}$ & 10 & 1 & 0.11 & & \\
\hline South Pole & $90.0 \mathrm{~S}$ & & 2810 & 0 & & & \\
\hline
\end{tabular}

of compressed air reference gases stored in high-pressure tanks. The long-term drift in the $\mathrm{O}_{2} / \mathrm{N}_{2}$ reference scale is constrained by the average concentration of a set of primary reference tanks, and has been estimated to be less than \pm 0.4 per meg $\mathrm{yr}^{-1}$ (Keeling et al., 2007). However, the $\mathrm{O}_{2} / \mathrm{N}_{2}$ reference scale may be subject to quasi-random variations of up to \pm 2 per meg due to thermal diffusive separation of $\mathrm{O}_{2}$ and $\mathrm{N}_{2}$ in the high-pressure gas tanks (Keeling et al., 2007). A systematic shift was documented following a laboratory move in early 1999 . The $\mathrm{O}_{2} / \mathrm{N}_{2}$ data presented here are on the $\mathrm{S} 2$ scale (June 2006 revision), which allows for an upwards shift of 2.6 per meg in the $\mathrm{O}_{2} / \mathrm{N}_{2}$ ratio delivered from our calibration tanks after the lab move. The magnitude of the estimated shift is supported by usage-related drift in short-term reference gases [see Keeling et al. (2007), figure 3].

Observations at each station are fit with a four-harmonic seasonal cycle and a stiff-spline interannual trend. To determine monthly averages, each point is adjusted to the 15 th of its month by "sliding" it parallel to the combined stiff-spline and fourharmonic fit; then the average for the month is computed. The four-harmonic seasonal fit is then subtracted to obtain seasonally adjusted, monthly data. Months with no data are filled in from the stiff-spline plus four-harmonic fit. Missing data are very rare except at La Jolla where the prevalent wind direction in the winter occasionally prevents appropriate sampling conditions throughout an entire month (Table 1). The global mean APO record was computed using a weighted average of individual station records, with the weights based on the latitudinal coverage and the area between latitude circles (Table 1). Because the number of available stations varies with time, different combinations of stations are used over different time frames. To eliminate stepwise offsets that would otherwise arise when transitioning from one station combination to another, we calculated an offset (always $<1$ per meg) for the first year of overlap and applied this to the earlier record. Means for the Northern and
Southern Hemispheres were constructed in an analogous way. Linear trends were calculated by least-squares fit to the global $\mathrm{CO}_{2}$ and $\mathrm{O}_{2} / \mathrm{N}_{2}$ records and then subtracted from the global and station $\mathrm{CO}_{2}, \mathrm{O}_{2}$ and APO data sets to create anomaly records. This approach highlights short-term variability, while preserving station-to-station differences. Finally, a 6-month running mean was applied to the anomaly records to smooth them.

\section{Observations of APO}

Variations in the monthly mean $\mathrm{O}_{2} / \mathrm{N}_{2}$ data are dominated by a seasonal cycle and a long-term trend of -18.4 per meg $\mathrm{yr}^{-1}$ (Fig. 2). A combination of ocean and terrestrial fluxes driven by photosynthesis and warming causes $\mathrm{O}_{2} / \mathrm{N}_{2}$ to rise in the spring and summer and fall in the autumn and winter (Keeling et al., 1993). Monthly mean APO data have features that are broadly similar to $\mathrm{O}_{2} / \mathrm{N}_{2}$ but of reduced magnitude (Fig. 3). The longterm trend in APO was -8.8 per meg $\mathrm{yr}^{-1}$ over 1992-2007. Interannual variations in both the $\mathrm{O}_{2} / \mathrm{N}_{2}$ and APO data sets were of much smaller magnitude than the seasonal cycles and long-term trend that dominate the monthly means.

Fluctuations in the APO anomaly at individual stations were coherent with each other, especially between adjacent stations and within a hemisphere (Fig. 4). The Northern Hemisphere stations had roughly the same pattern of oscillating anomalies over much of the record. The strongest feature was an increase in the APO anomaly beginning in the late 1990s, followed by an abrupt drawdown in 2000-01. A similar but much weaker feature is evident in the APO anomalies at Southern Hemisphere stations. A change in atmospheric APO concentration can be converted to a maximum implied flux in units of moles by multiplying the change in $\delta$ APO by the total moles of dry gas in the atmosphere and the mole fraction of oxygen in the atmosphere (Manning and Keeling, 2006). The resulting APO flux is a combination of $\mathrm{O}_{2}, \mathrm{CO}_{2}$ and $\mathrm{N}_{2}$ fluxes: $F_{\mathrm{APO}}=F_{\mathrm{O}_{2}}+$ 


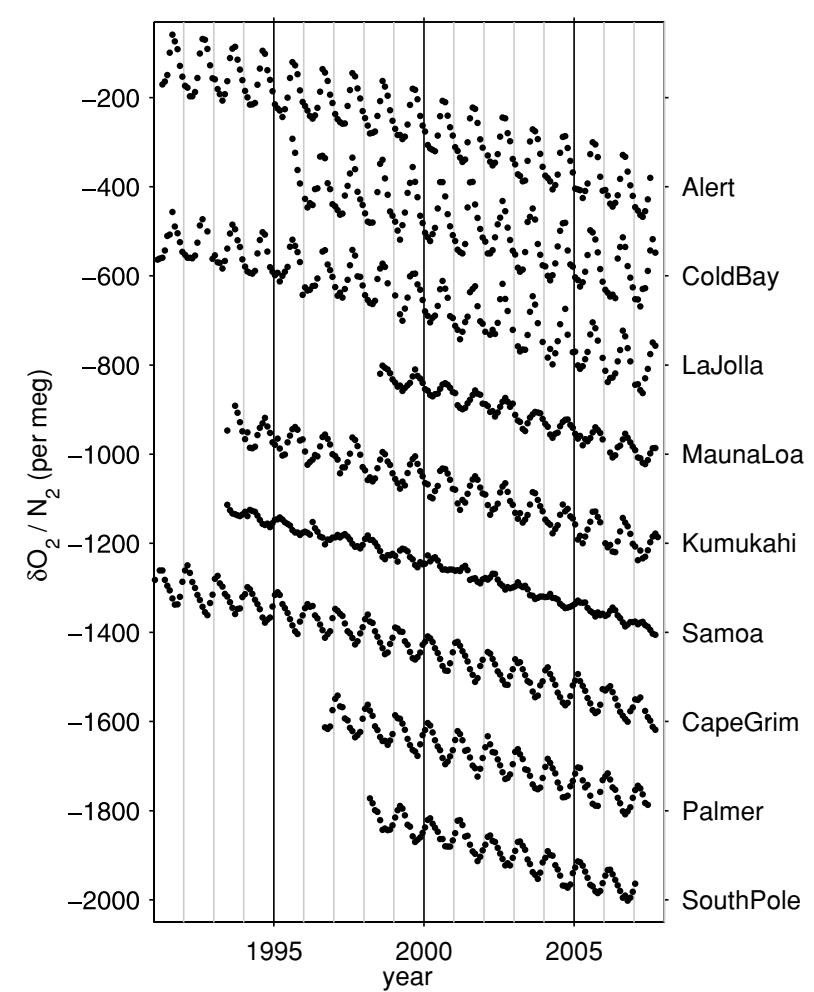

Fig. 2. Points are monthly averages of the atmospheric $\mathrm{O}_{2} / \mathrm{N}_{2}$ ratio at stations in the Scripps flask sampling network. Stations are plotted from northernmost at the top to southernmost at the bottom. Data from Alert are shown on the Scripps Institution of Oceanography reference scale. The scales of all other stations are offset from the station above by -200 per meg.

$1.1 F_{\mathrm{CO}_{2}}-0.268 F_{\mathrm{N}_{2}}$. Calculated this way, the maximum APO flux out of the atmosphere implied by the 2000-01 decrease in the global APO anomaly is $3.3 \times 10^{14} \mathrm{~mol} \mathrm{APO}$, assuming a well-mixed atmosphere. The data inversion of Rödenbeck et al. (2008), which uses the TM3 atmospheric transport model to realistically simulate atmospheric mixing, retrieves an anomalous flux of $1.7 \times 10^{14}$ moles APO into the oceans from 2000 to early 2001. As discussed in the next section, this flux is likely to be primarily driven by air-sea exchanges of $\mathrm{O}_{2}$.

The observed interannual variability in APO is on the order of 5-10 per meg over several years, which is not much larger than some of the adjustments we have made to our calibration scale due to calibration drift (Keeling et al., 2007). If drift in our $\mathrm{O}_{2} / \mathrm{N}_{2}$ reference scale was the dominant factor causing the apparent interannual APO variability, then we would expect records at different stations to correlate with each other to about the same degree, regardless of their spatial relationship to each other. To test this, we calculated zero-lag correlations and significance between pairs of stations. Standard methods of calculating the significance of correlations require that data points be independent of each other. However, like many geochemical time-series, points in our time-series are not independent of the

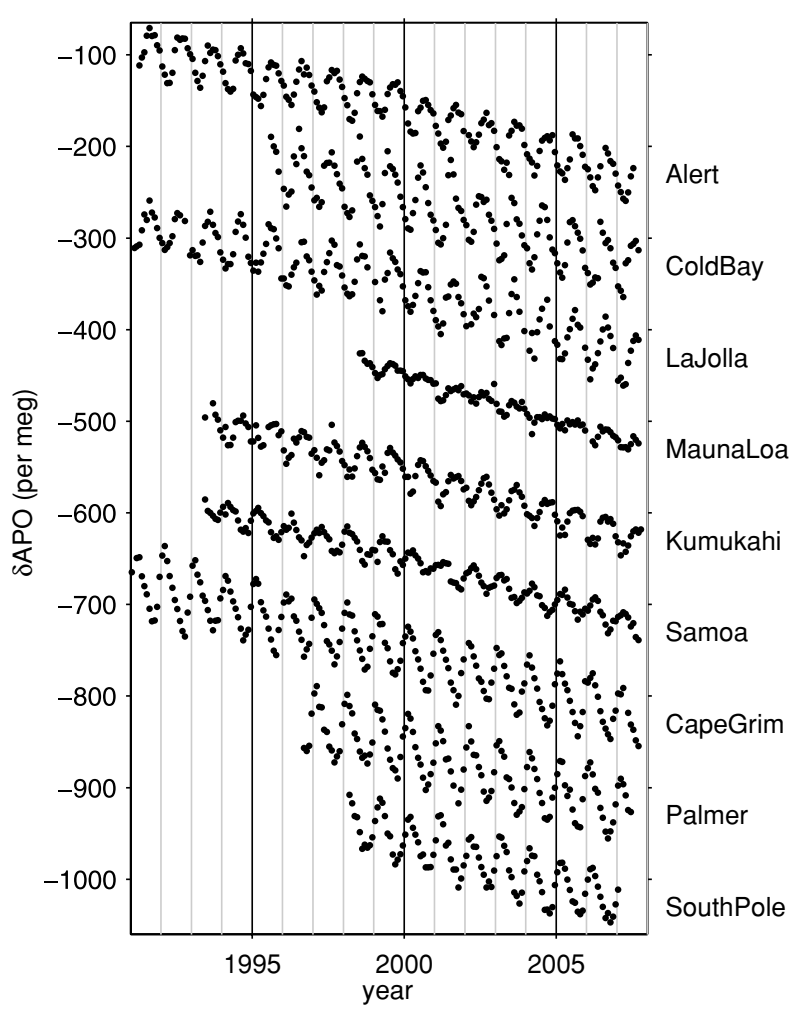

Fig. 3. Points are monthly averages of APO at stations in the Scripps flask sampling network. Data from Alert are shown on the Scripps Institution of Oceanography reference scale. The scales of all other stations are offset from the station above by -100 per meg.

points surrounding them, both due to the importance of longer timescale processes and due to filtering of the data. To determine the significance of the correlations, we used a Monte Carlo method to produce an ensemble of synthetic time-series with random phase information but the same spectral character as the time-series at one station in the pair (Ebisuzaki, 1997). This ensemble of synthetic time-series was correlated with the observed time-series at the second station to create a distribution of correlation coefficients. Our measure of significance, expressed as a $\mathrm{p}$-value, is the fraction of the correlations in this distribution that are greater than our observed correlation for the actual pair of stations. A lower significance value indicates a more significant correlation, with a significance value of 0.05 equivalent to a $95 \%$ confidence interval.

Correlations between pairs of stations within the same hemisphere were generally above 0.5 with higher significance values $(\mathrm{p}<0.04)$, particularly within the Northern Hemisphere, compared with lower and less significant correlations between stations in opposite hemispheres (Fig. 5). The within-hemisphere correlations are similar to those Nevison et al. (2008) derived from an ocean ecosystem and atmospheric transport model, though our interhemispheric correlations are somewhat higher. We take the larger, more significant within-hemisphere correlations as an indication that much of the interannual variability that 


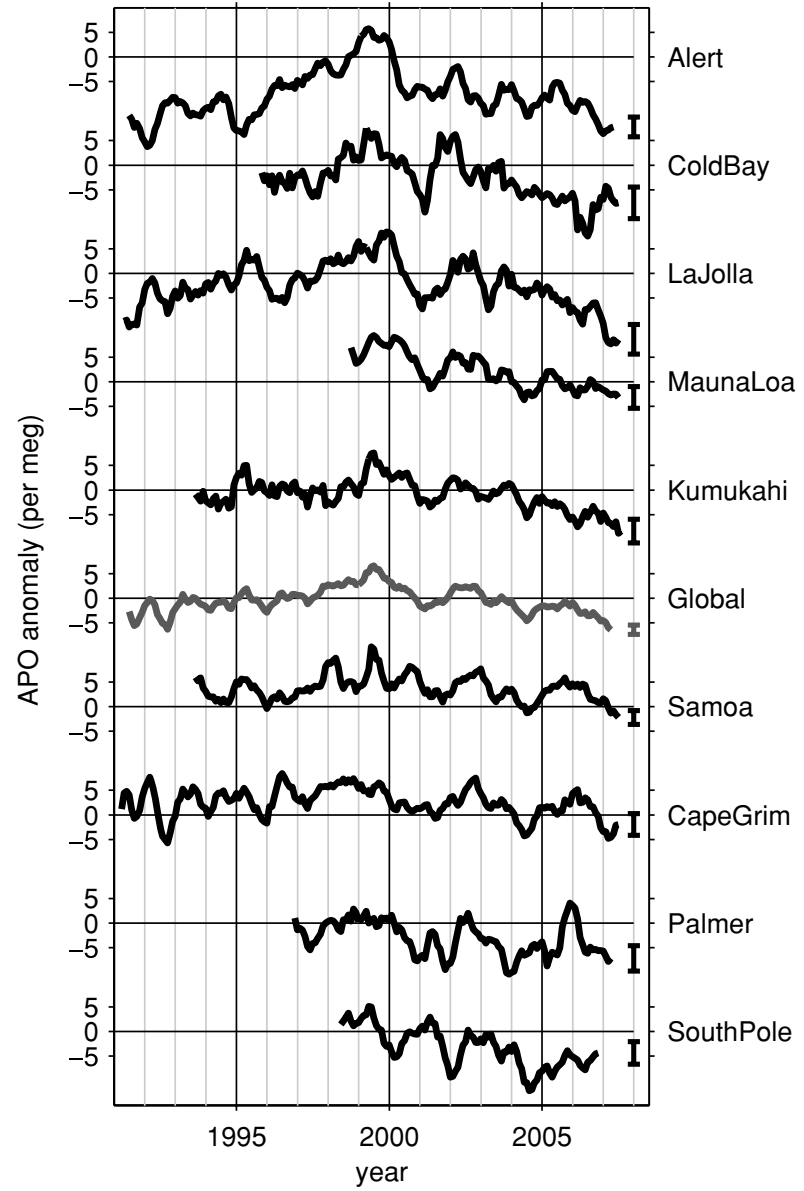

Fig. 4. Interannual anomalies in APO at sampling stations, derived by subtracting the same linear trend from seasonally detrended data at each station and smoothing with a 6-month running mean. Stations are plotted from northernmost at the top to southernmost at the bottom with the global mean APO anomaly plotted between hemispheres. Error bars represent the estimated imprecision of the 6-month running mean based on the typical scatter of the monthly means around the smooth long-term trend. This estimate implicitly allows for analytical imprecision, random sampling, storage artefact effects and short-term (synoptic) atmospheric variability.

we observe is a real environmental signal and not the result of analytical artefacts. Rödenbeck et al. (2008) also conclude that the interannual variability in APO fluxes is robust to calibration drift based on an inversion of the observations, with the mean global APO concentration removed.

The interhemispheric gradient in APO is a particularly robust measure of interannual variability, because differences between stations should not be affected by drift in the calibration scale. A time-latitude plot of the APO anomaly shows appreciable variation over time (Fig. 6). On average, APO exhibited a maximum at low latitudes that decreased towards the north and south. The strong increase and abrupt drawdown in Northern Hemisphere APO previously highlighted is evident in this figure as a flat-
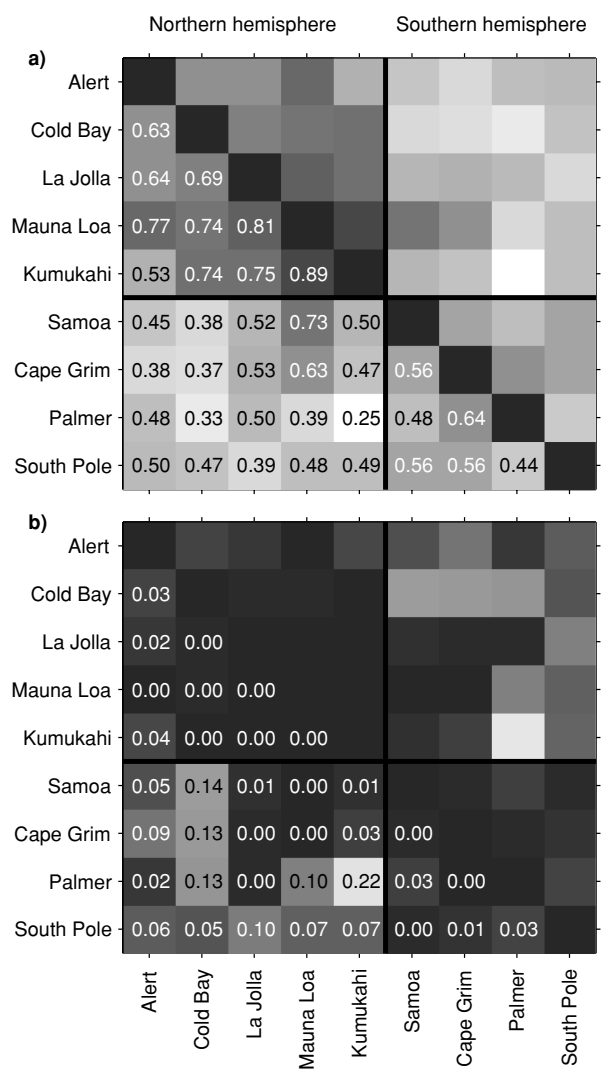

Fig. 5. (a) Zero-lag correlation between pairs of stations of the APO anomaly time-series shown in Fig. 4. For emphasis, highest correlations are shown with darker shading. Stations are listed northernmost to southernmost with the boundary between hemispheres marked by a heavy line. This figure is symmetrical about the diagonal.

(b) Significance of zero-lag correlations expressed as a p-value, calculated by the Ebisuzaki (1997) method. Most significant correlations are shown with darker shading.

tening of the gradient within the Northern Hemisphere during 1998-2000, followed by an abrupt strengthening. The Southern Hemisphere gradient also appeared flatter around 1999. A simple time-series that captures many of the features of the APO gradient can be constructed from the difference in the mean APO of each hemisphere (Fig. 7). This interhemispheric APO difference ranges from less than -10 per meg to near zero over the time period of our data. The strong decrease in the Northern Hemisphere APO anomaly around 2000-01 is evident as a strengthening of the interhemispheric difference to more negative values.

\section{Causes of APO variability}

Because the tracer APO is largely unaffected by terrestrial exchanges or fossil-fuel combustion at frequencies of a few years, we look to the ocean for the causes of the variability we observe, considering three possibilities: variability in ocean 


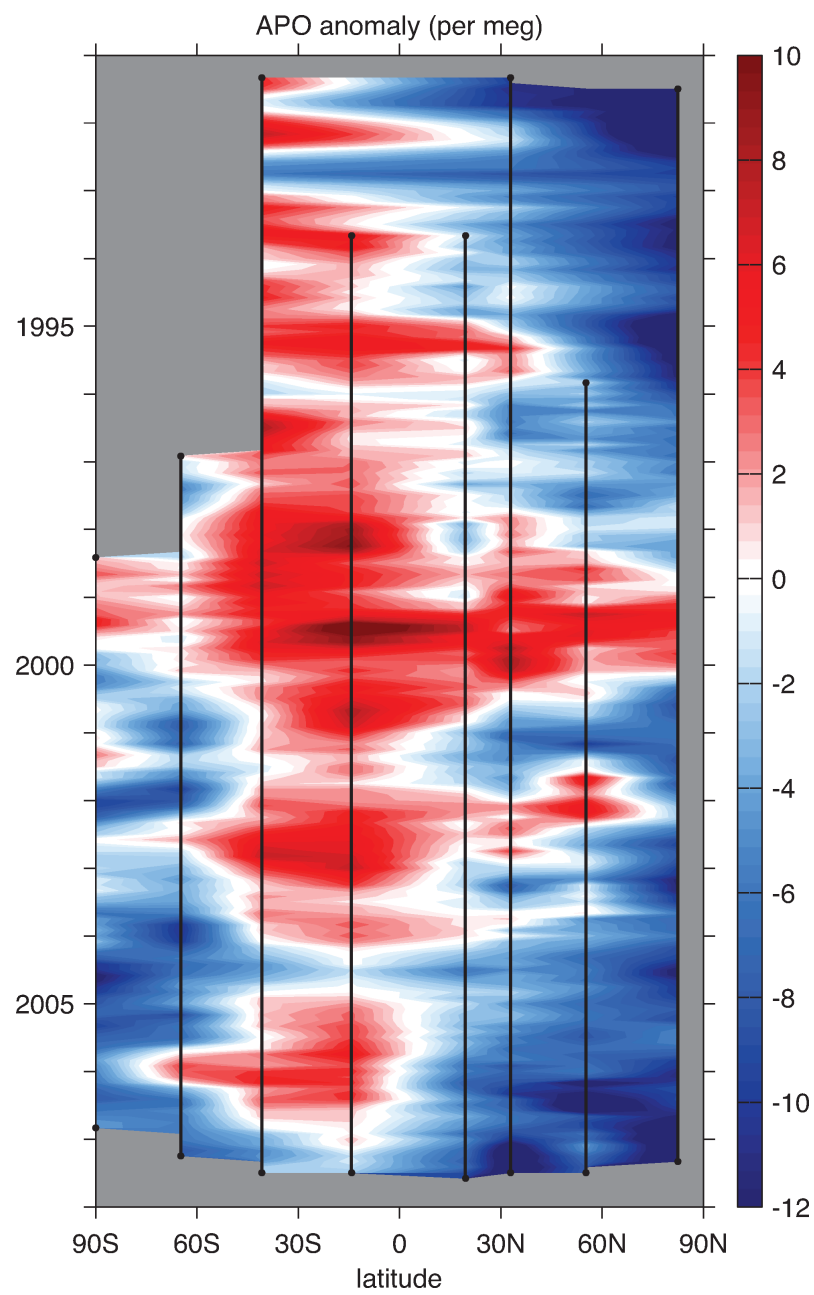

Fig. 6. Time-latitude plot of the APO anomaly linearly interpolated between stations. Thin lines indicate the time period over which data are available from each station. Grey areas indicate no data with which to calculate a gradient. Note that certain features not resolved by the Scripps flask sampling network do not appear, such as the equatorial bulge (Battle et al., 2006; Tohjima et al., 2005).

ventilation, biological productivity and heat content. Variations in atmospheric transport may also play a role, though we believe a small one as discussed below. Warming of the ocean releases both $\mathrm{O}_{2}$ and $\mathrm{CO}_{2}$ from the water, which would force an increase in APO, while cooling would force a decrease. Warming also releases $\mathrm{N}_{2}$ which partly counteracts the effect of the $\mathrm{O}_{2}$ release on APO. The effect of warming on $\mathrm{O}_{2}$ and $\mathrm{CO}_{2}$ fluxes has previously been estimated on decadal timescales in calculations from atmospheric measurements of the partitioning between land and ocean sinks of anthropogenic $\mathrm{CO}_{2}$ (Manning and Keeling, 2006). Because of differences in their air-sea equilibration timescales, changes in ocean productivity produce larger air-sea fluxes of $\mathrm{O}_{2}$ than $\mathrm{CO}_{2}$, which would influence APO (Keeling and Severinghaus, 2000). An increase in surface production would

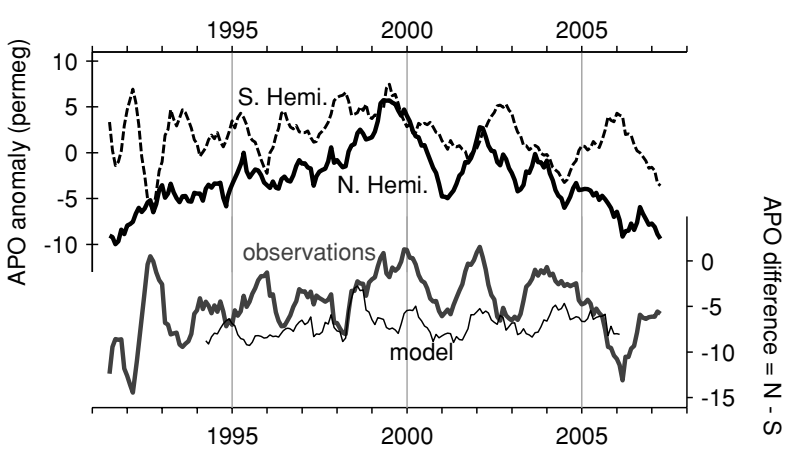

Fig. 7. Upper panel shows weighted mean APO in each hemisphere. See Table 1 for station weightings. Lower panel shows the interhemispheric APO difference constructed from the difference between the Northern and Southern hemispheres means. The thick line is the difference derived from our observations, while the thin line is the difference calculated from a forward run of the TM3 model using interannually varying winds but climatological air-sea APO fluxes (Rodenbeck et al., 2008).

cause an almost immediate flux of $\mathrm{O}_{2}$ to the atmosphere that would only be partially compensated by a flux of $\mathrm{CO}_{2}$ into the ocean over the following few years.

Although respiration is effectively the opposite of photosynthesis, the exposure of deeper, respiration-dominated waters to the surface by ventilation may have a substantially different impact on APO than the inverse of the marine productivity scenario considered above. First, ventilation events are typically associated with deeper mixed layers and would therefore tend to amplify the air-sea exchange of $\mathrm{O}_{2}$, which equilibrates more rapidly than $\mathrm{CO}_{2}$. Second, deeper waters can be conditioned by prior exposure to the surface, such as from convective overturn in previous winters. Conditioning will reduce the deficit in $\mathrm{O}_{2}$ relative to excesses in $\mathrm{CO}_{2}$, following their different equilibration rates. At steady state, and averaged over an annual cycle, airsea fluxes driven by production and ventilation should balance (Bender et al., 1998). However, a sudden increase in ventilation after a period of reduced ventilation could result in initially large air-sea $\mathrm{O}_{2}$ fluxes that are only balanced by $\mathrm{CO}_{2}$ fluxes over multiple years of renewed ventilation. The result would be a decrease in the APO anomaly that recovers to prior levels only after several years or more. This mechanism has been shown by Verdy et al. (2007) to be important in driving interannual air-sea $\mathrm{O}_{2}$ and $\mathrm{CO}_{2}$ fluxes in a biogeochemical model of the Southern Ocean.

Interannual variability in atmospheric transport probably contributes some to the observed variability in the APO gradient, but it is unlikely the main source of variability. A forward run of the TM3 transport model described in Rödenbeck et al. (2008), using climatological air-sea fluxes of $\mathrm{O}_{2}$ and $\mathrm{CO}_{2}$ but interannually varying meteorological fields from the NCEP reanalysis (Kalnay et al., 1996) was subsampled at the times and locations of our flask samples. These data were processed in an identical 
manner to the observations, as described above. The interannual variability in the modelled interhemispheric APO difference is substantially smaller than the observed variability (Fig. 7). The correlation between the observed and modelled interhemispheric APO differences is 0.34 ( $p=0.005)$. If the $1997-98 \mathrm{El} \mathrm{Niño} \mathrm{is}$ removed from the time-series, the correlation remains the same but the significance drops to $\mathrm{p}=0.04$. The lower variability in the modelled interhemispheric APO difference and the level of correlation with the observations indicates that the majority of the variance is likely not explained by atmospheric transport variability. We proceed with the assumption that the interannual variability in APO in the observations is driven principally by air-sea fluxes of APO.

\subsection{Ventilation}

Several lines of evidence suggest that a reduction and then increase in both North Atlantic and North Pacific ventilation may have caused the fluctuations in the Northern Hemisphere APO anomaly around 1999-2001. Winters in the early 1990s produced deep convection to depths of about $2300 \mathrm{~m}$ in the Labrador Sea as demonstrated by annual hydrographic surveys, but after 1994 convection depths were shallow $(\sim 1000 \mathrm{~m})$ due to lower wintertime heat losses linked to a low North Atlantic Oscillation (NAO) index (Lazier et al., 2002). The winter of 1999-2000 was a clear exception in this time period of shallow convection. Heat losses were higher in this winter and convection reached depths of $1600 \mathrm{~m}$, producing a distinct water mass that was observed for at least five more years (Yashayaev, 2007). Annual hydrographic surveys of the Greenland Sea also recorded an abrupt increase in convective depth in the winter of 1999-2000 (Ronski and Budéus, 2005), suggesting that this winter was characterized by wide-spread deep ventilation in the North Atlantic. The mean APO anomaly in the Northern Hemisphere began to fall in the winter of 1999-2000 from its maximum value. The record at Alert, which should be well located to pick up Atlantic phenomena, and records at Cold Bay and La Jolla all show decreases, beginning in late 1999 or very early 2000 . We hypothesize that ventilation in the North Atlantic during 1999-2000 of water lay- ers that had been isolated from the atmosphere for some years, resulted in high fluxes of $\mathrm{O}_{2}$ into the ocean and could account for the beginning of the decrease in the Northern Hemisphere APO anomaly at this time.

The following winter, 2000-01, was particularly severe in the western North Pacific, and we hypothesize that this much colder winter allowed denser isopycnals than normal to be ventilated, resulting in higher fluxes of oxygen from the atmosphere into the ocean. Air temperatures at the Vladivostok World Meteorological Organization station were extremely cold $\left(3-5^{\circ} \mathrm{C}\right.$ below normal) during the winter of 2000-01 (Talley et al., 2003). Consequently, anomalously cold sea-surface temperatures were observed over much of the Pacific north of $40^{\circ} \mathrm{N}$ (Fig. 8), including the area of the Western Pacific where the densest waters in the North Pacific are ventilated. The 2000-01 winter had the coldest SSTs in this region of any year in our time-series. Tohjima et al. (2008) also measure large decreases in APO in late 2000 at two Western Pacific sites, Hateruma Island and Cape Ochi-ishi in Japan, which they attribute, partially based on our own analysis, to increased ventilation caused by colder SSTs in this winter.

The 10.6 per meg decrease in the Northern Hemisphere APO anomalies in 1999-2001, if driven by fluxes of $\mathrm{O}_{2}$, implies an $\mathrm{O}_{2}$ flux into the ocean of $2 \times 10^{14} \mathrm{~mol}$ in the Northern Hemisphere. Very roughly, perhaps half this flux might have been taken up by the North Atlantic and half by the North Pacific. Biogeochemical/circulation models of the North Atlantic have attributed fluctuations of approximately $4 \times 10^{13} \mathrm{~mol} \mathrm{O}_{2} \mathrm{yr}^{-1}$ to variability in convection depths (McKinley et al., 2003; Friedrich et al., 2006). Although this is somewhat smaller than our suggested flux, it may be that these models underestimate APO flux variability similar to the OPA-PISCES-T biogeochemistry/circulation model (Rödenbeck et al., 2008). The suggested North Pacific flux can be placed in the context of the typical hydrography of the region. The World Ocean Atlas (Levitus, 2005) March climatology shows that the densest isopycnals to outcrop in the open North Pacific over an appreciable area are $\sigma_{\theta} 26.4$ and 26.5, with an outcrop area of $4.1 \times 10^{12} \mathrm{~m}^{2}$ having a density greater than $\sigma_{\theta}$ 26.4. For this area to take up $10^{14}$ extra moles of $\mathrm{O}_{2}$, a flux of $8 \mathrm{~mol} \mathrm{O}_{2} \mathrm{~m}^{-2}$ month $^{-1}$ over the three winter months would

mean January-March 2001 SST Anomaly

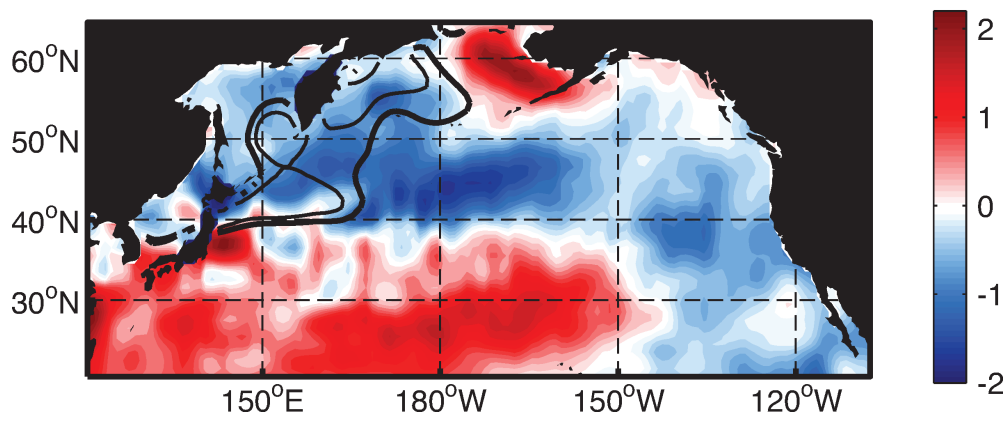

Fig. 8. Mean sea-surface temperature anomalies $\left({ }^{\circ} \mathrm{C}\right)$ in the North Pacific during January-March 2001 from the NOAA Optimum Interpolation SST database (OI.v2). Contour lines show the March climatological location of outcropping isopycnals at $\sigma_{\theta}=26.4$ (thicker line) and at $\sigma_{\theta}=26.5$ (thinner line) from the World Ocean Atlas (Levitus, 2005). 
be required. Assuming a gas exchange coefficient of $9 \mathrm{~m} \mathrm{~d}^{-1}$ for this area in the winter (Kawabata et al., 2003), the air-sea gradient would need to be about $30 \mu \mathrm{mol} \mathrm{kg}{ }^{-1}$ greater than normal. The mean climatological dissolved apparent oxygen utilization (AOU) on the $\sigma_{\theta} 26.4$ and 26.5 isopycnals in this outcrop area is about $20 \mu \mathrm{mol} \mathrm{kg}{ }^{-1}$, while that on the $\sigma_{\theta} 26.6$ isopycnal is $50 \mu \mathrm{mol} \mathrm{kg}{ }^{-1}$ higher than that. If winter conditions were severe enough to bring the $\sigma_{\theta} 26.6$ isopycnal to the surface over much of this ventilation region, an $\mathrm{O}_{2}$ flux into the ocean of similar magnitude to that observed could potentially be generated. The NOAA Optimum Interpolation SST database suggests that temperatures in early 2001 were at least $1^{\circ} \mathrm{C}$ colder over much of this outcropping region of the North Pacific (Fig. 8), which could change the density by at least $0.1 \sigma_{\theta}$.

Increased ventilation of other water masses in the North Pacific may also have contributed to the ocean's uptake of atmospheric $\mathrm{O}_{2}$ in the winter of 2000-01. Talley et al. (2003) observed unusually large renewal of bottom waters by brine rejection in the East/Japan Sea in February 2001, with an associated strong increase in dissolved $\mathrm{O}_{2}$ at densities up to $\sigma_{\theta} 27.7$. The unusually cold air and sea-surface temperatures may also have increased ventilation in the Okhotsk Sea, where North Pacific intermediate water at $\sigma_{\theta}$ 26.65-27.4 is formed by brine rejection (Talley, 1997; Shcherbina et al., 2004). There are also indications that increased ventilation of lower density waters such as subtropical mode water (STMW) at $\sigma_{\theta} 25.0-25.5$ could have played a role in the ocean's uptake of APO. The analysis of Qiu and Chen (2006) shows that wintertime mixed layer depths in the STMW formation region south of the Kuroshio, reached depths $\sim 50 \mathrm{~m}$ deeper in the winter of 2000-01 than they had for several years previously, likely exposing a larger mass of lower oxygen water to the atmosphere than usual.

Repeat hydrographic observations of dissolved $\mathrm{O}_{2}$ have identified significant changes in the North Pacific and other ocean basins on decadal timescales (Emerson et al., 2001; Ono et al., 2001; Johnson and Gruber, 2007), but the spatial sparsity of the observations makes estimates of inventory changes difficult. Deutsch et al. (2006) used a hindcast model to predict changes in North Pacific dissolved $\mathrm{O}_{2}$ due to ventilation, circulation and productivity changes, finding that changes in ventilation and gyre circulation dominate variability in the lower thermocline $\left(\sigma_{\theta} \sim 26.6\right)$ where the largest changes in dissolved $\mathrm{O}_{2}$ have been observed. Their model predicts inventory changes on the order of $7 \times 10^{13} \mathrm{~mol} \mathrm{O}_{2} \mathrm{yr}^{-1}$ in some years. This is near the magnitude of the fluxes we derive from our atmospheric observations, lending support to the idea that the North Pacific is capable of relatively large interannual variability in air-sea $\mathrm{O}_{2}$ fluxes.

\subsection{Comparison to climate indices}

The inversion results of Rödenbeck et al. (2008) derive tropical APO fluxes that show a correlation to El Niño indices (APO fluxes out of the ocean during El Niño events). In non-El Niño

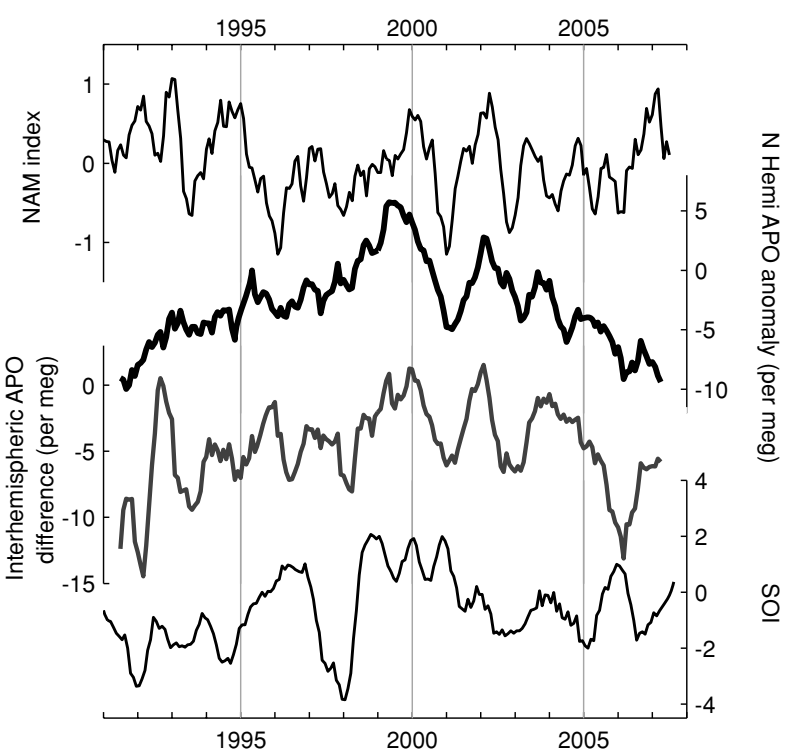

Fig. 9. Uppermost panel shows the Northern Annular Mode index (also known as the Arctic Oscillation). Next panel down shows the mean Northern Hemisphere APO anomaly. Next panel down shows the interhemispheric APO difference. Lowest panel shows the Southern Oscillation Index. Climate indices were obtained from the NOAA Climate Prediction Center website (http://www.cpc.ncep.noaa.gov/) and have been smoothed with a 6-month running mean to match the smoothing of the APO time-series.

years, the equatorial upwelling zone is likely to be a sink for APO caused by the upwelling of low $\mathrm{O}_{2}$ waters, while the latitudinal bands outside this zone, where biological productivity and warming dominate, are likely to be a source of APO. During El Niño events, the fluxes in both regions would be expected to weaken. The APO observations themselves do not contain striking visual evidence of particular events such as the strong 1997-98 El Niño (Fig. 4), though the Scripps sampling network is sparse in the tropics. Only the Samoa record shows a distinct feature in 1997-98, which creates a very brief strengthening of the interhemispheric APO difference at this time. The interhemispheric APO difference has a weak correlation of $0.30(\mathrm{p}=$ 0.12), with the Southern Oscillation Index (SOI) over 1991-2007 (Fig. 9). Correlations of individual stations with the SOI are not any stronger. While the connection between APO variability in our observations and El Niño appears weak, our analysis focuses on hemispheric means and the interhemispheric difference, none of which highlights tropical fluxes. The analysis of Rödenbeck et al. (2008), using an inversion method that highlights differences between stations, shows that El Niño likely does play an important role in interannual APO variability in the tropics.

We find only low correlations between Northern Hemisphere climate indices and APO anomalies or interhemispheric differences. The Northern Annular Mode index (NAM, same as Arctic Oscillation/AO index) is shown as an example (Fig. 9) with a 
correlation of $0.10(p=0.22)$, with the mean Northern Hemisphere APO anomaly and a correlation of $0.26(\mathrm{p}=0.10)$ with the interhemispheric APO difference. Similar to the Northern Hemisphere APO anomaly, the NAM index has a maximum in 2000 followed by an extreme minimum in 2001, but the NAM has other strong features that do not appear to be mirrored in the APO time-series.

Indices such as the NAM may not be straightforward proxies for APO changes driven by ventilation. The NAM index is the leading principal component time-series of monthly Northern Hemisphere sea level pressures. A low NAM index is associated with a higher frequency of cold events over eastern Asia and Siberia, while a high NAM index is associated with cold events over Greenland and Newfoundland (Thompson and Wallace, 2001). This means that both extreme low and high NAM events may be associated with increased ventilation in either the North Pacific or the North Atlantic, respectively. For the 1999-2001 feature, the NAM index was very high during the 1999-2000 winter when North Atlantic ventilation appears to have been active and very low during the 2000-01 winter when North Pacific ventilation may have been active. The Northern Hemisphere APO anomaly decreased during both these years. Further, we hypothesize that anomalous APO fluxes will be most affected by a situation in which ventilation has been reduced for several years and then suddenly strengthens. The early 1990s were characterized by repeated winters of deep convection in the North Atlantic and a sustained high NAM index. This situation would not have been expected to significantly decrease the APO anomaly, because deep waters would not have had the opportunity to build up a high $\mathrm{O}_{2}$ deficit, and in fact the APO anomaly was stable or increasing at that time. Near-zero NAM indices in the late 1990s were associated with shallow convection in the North Atlantic, warm to neutral SST anomalies in the North Pacific, and increasing APO anomalies. The possible sensitivity of APO to both low and high NAM indices and to sudden changes to extreme values likely degrades any simple correlation between the time-series, though the relationship between certain features of these two time-series seems to match expectations.

\subsection{Marine productivity changes}

We evaluate the possible contribution of marine biological productivity changes to APO variability through comparison to satellite-based productivity estimates. Monthly-averaged global maps from September 1997 were obtained of net primary production (NPP) over the euphotic zone, estimated using the standard Vertically Generalized Production Model algorithm (Behrenfeld and Falkowski, 1997), AVHRR sea-surface temperature fields, and SeaWIFS chlorophyll and photosynthetically active radiation (PAR). A monthly climatology was constructed from the available data and subtracted from the data set to yield production anomalies, which were then integrated to yield a to-

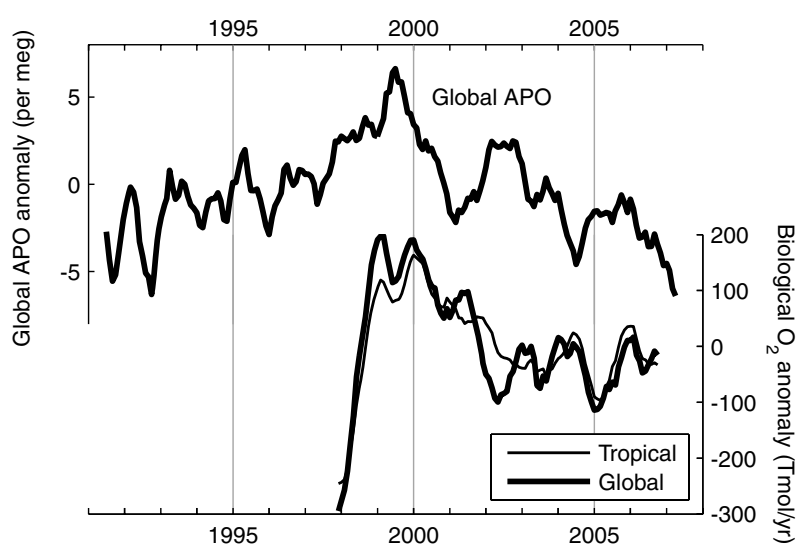

Fig. 10. Upper panel shows the mean global APO anomaly (in per meg). Lower panel shows an estimate of the global anomaly in net

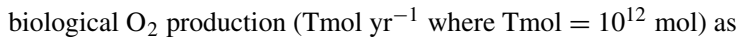
derived from satellite-based estimates of net primary production [SeaWIFS data processed using the Behrenfeld and Falkowski (1997) standard VGPM algorithm]. Both the global integral of the anomaly and just the tropics $\left(20^{\circ} \mathrm{N}-20^{\circ} \mathrm{S}\right)$ are shown. All three time-series were smoothed with a 6-month running mean.

tal productivity anomaly time-series for different latitude bands. Conversion from carbon to oxygen units used a ratio of 1.44 $\mathrm{O}_{2}$ : C for marine photosynthesis (Anderson, 1995).

Increased productivity may have contributed to the increase in global APO in 1998-99, but could not have been responsible for the abrupt drawdown in APO in 2000-01 (Fig. 10). As shown by Behrenfeld et al. (2006), variation in globally-integrated biological production derived from these satellite-based estimates is dominated by variations in tropical $\left(20^{\circ} \mathrm{N}-20^{\circ} \mathrm{S}\right)$ productivity, which are in turn mainly driven by El Niño/La Niña events. We find a correlation of $0.93\left(\mathrm{p}<10^{-4}\right)$ between the global and tropical anomaly time-series we derived, and a correlation of $0.84\left(\mathrm{p}=10^{-4}\right)$ between the tropical anomaly time-series and the SOI. The biological productivity time-series begins with anomalously low productivity during the El Niño of 1997 and then moves abruptly to several years of anomalously high production during the sustained La Niña of 1999-2001. The timing of increased production roughly corresponds with an increase in the APO in the Northern Hemisphere. However, estimated productivity remains high during the abrupt APO drawdown in 200001 , and the overall correlation between the global APO anomaly and globally integrated productivity was low at $0.13(\mathrm{p}=0.27)$. This suggests that marine productivity variability is not the dominant factor controlling interannual APO variations. The magnitude of potential air-sea fluxes of photosynthetically derived $\mathrm{O}_{2}$ $\left(\sim 10^{14} \mathrm{~mol} \mathrm{yr}^{-1}\right)$ is comparable to the magnitude of the fluxes we calculate from the observations and that Rödenbeck et al. (2008) derive from their model inversion. However, because $\mathrm{O}_{2}$ production associated with NPP is compensated by heterotrophic respiration in surface waters, the potential for NPP to drive 
air-sea $\mathrm{O}_{2}$ fluxes is actually smaller than implied by this comparison. Also, because tropical productivity is driven by upwelling, which brings low $\mathrm{O}_{2}$ water to the surface, the photosynthetically derived $\mathrm{O}_{2}$ flux is further compensated by $\mathrm{O}_{2}$ uptake of newly exposed deeper waters.

\subsection{Global heat fluxes}

It has been suggested that global air-sea fluxes of $\mathrm{O}_{2}$ and heat may be correlated on interannual timescales (Bopp et al., 2002; Plattner et al., 2002). To test whether such an effect could be driving the observed APO changes, we compared the global mean APO record to estimates of world ocean heat content from Levitus et al. (2005) and from Willis, personal communication (2008) including recent, preliminary corrections for biases discovered in XBT and ARGO data (Willis et al., 2004, 2007). Based solely on solubility effects at the average ocean SST of $17^{\circ} \mathrm{C}$ and assuming instantaneous gas exchange, an outgassing of $3.4 \mathrm{nmol}$ APO per Joule increase in heat content could be expected, dominated by $\mathrm{CO}_{2}$ fluxes.

Both heat content estimates show an increasing trend from 1996-2003, while the global APO anomaly also increases over the late 1990s but then returns to former levels (Fig. 11). The increase of $\sim 90 \mathrm{ZJ}$ in heat content could produce a purely solubility driven flux of $\sim 3 \times 10^{14} \mathrm{~mol}$ APO, close to the observed APO anomaly increase. However, the observed heat content changes cannot explain the 2000-01 decrease in APO. If variability in wintertime ventilation is the main driver of the interannual variability in APO, we may not expect to find a strong association between global heat content and APO variations. While strong ventilation years are generally colder years, the variability in total ocean heat content is likely dominated by other factors. Also,

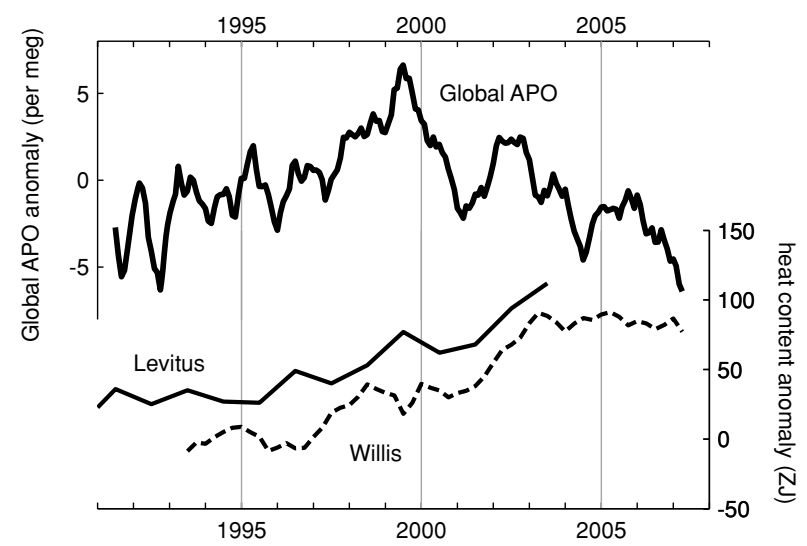

Fig. 11. Upper panel shows the mean global APO anomaly (in per $\mathrm{meg})$. The lower panel shows estimates of the global ocean heat content anomaly (in ZJ where $1 \mathrm{ZJ}=10^{21} \mathrm{~J}$ ) from Levitus et al. (2005) and an updated data set from Willis (personal communication, 2008) including preliminary corrections for recent biases found in XBT and ARGO data sets (Willis et al., 2004, 2007). the effect of interannual heat content variability on $\mathrm{CO}_{2}$ fluxes would be damped by the slow air-sea equilibration timescale of $\mathrm{CO}_{2}$. In addition, different $\mathrm{O}_{2}$ /heat relationships operating in different regions may decouple APO and heat content variability. It seems likely, for example, that different $\mathrm{O}_{2}$ /heat relationships operate in the Tropical Pacific, which is heavily driven by El Niño variability, compared with higher latitudes (Keeling and Garcia, 2002; McKinley et al., 2003). Even if heat and APO or $\mathrm{O}_{2}$ fluxes are not associated with each other globally on the 2-5 yr timescale, this does not rule out an association on decadal and longer timescales, as has been assumed in decadal $\mathrm{O}_{2}$ budgets (Bopp et al., 2002; Keeling and Garcia, 2002; Plattner et al., 2002; Manning and Keeling, 2006).

\section{Conclusions}

We have presented observations of interannual variability in APO from atmospheric measurements of $\mathrm{O}_{2}$ and $\mathrm{CO}_{2}$, which must be related to variability in air-sea fluxes of this tracer. As detected by changes in the gradient between stations and in agreement with Rödenbeck et al. (2008), this variability represents a real environmental change and not a laboratory artefact due to calibration drift. This paper has focused on explaining the main feature in the Northern Hemisphere APO anomaly, a rise in the late 1990s followed by a rapid drawdown in 19992001. Evidence of deeper convection depths than normal in the winter of 1999-2000 in the North Atlantic followed the next year by a severe winter in the Western North Pacific suggests that ventilation of denser isopycnals than normal played a role in the abrupt APO decrease. Water masses that have been isolated from the atmosphere for several years, have the potential to build up a significant dissolved $\mathrm{O}_{2}$ deficit that would lead to high air-to-sea $\mathrm{O}_{2}$ fluxes when severe winters allow these water masses to surface. Both a rough calculation of the possible effect of ventilation in the western North Pacific and the model derived $\mathrm{O}_{2}$ inventory changes of Deutsch et al. (2006) suggest that the air-sea fluxes we derive from the observations can be reasonably explained by this increased ventilation hypothesis. In contrast, the observed variability in the global mean APO anomaly and interhemispheric difference are only weakly correlated with El Niño indices, marine productivity changes and estimates of global oceanic heat content. Attribution of observed interannual APO variations to ventilation events should allow for improved model simulations of APO and by extension $\mathrm{CO}_{2}$, as well as aiding data-based calculations of interannual variability in the oceanic carbon sink.

\section{Acknowledgments}

We wish to thank Bill Paplawsky, Adam Cox, Kim Bracchi, Stephen Walker, Laura Katz, Jill Cooper, Elizabeth McEvoy, Chris Atwood and Steve Shertz for their assiduous efforts in support of atmospheric $\mathrm{O}_{2}$ and $\mathrm{CO}_{2}$ measurements from the Scripps 
flask sampling network. We thank Neil Trivett, Doug Worthy, Roger Francey, Laurie Porter, Russ Schnell, Mark Winey, Taylor Ellis, Michael Bender, Pieter Tans, Tom Conway, Chuck Yates, Jerry Painter, and Alane Bolenbacher, as well as staff at the Canadian Baseline Program, the NOAA/CMDL programs at Mauna Loa Observatory and American Samoa, the U.S. National Weather Service at Cold Bay, Alaska, the Cape Grim Baseline Station, and the U.S. Antarctic Program for the collection of air samples. We are very grateful to Christian Rödenbeck for his forward model runs investigating the effect of transport variability. We thank NOAA for making available their OI.v2 SST estimates (http://www.cdc.noaa.gov/), records of climate indices (http://www.cpc.ncep.noaa.gov/), and Levitus ocean heat content data (http://www.nodc.noaa.gov/). NPP estimates were obtained from the Oregon State Ocean Productivity site (http://web.science.oregonstate.edu/ocean.productivity/). Josh Willis kindly provided his heat content estimates to us. This work was supported by the National Science Foundation (NSF) under ATM-872037, ATM-9309765, ATM-9612518, ATM-0000923, ATM-0330096, ATM-0651834, by the Environmental Protection Agency (EPA) under IAG\#DW49935603-01-2, and by the National Oceanic and Atmospheric Administration (NOAA) under NA77RJ0453A and OAR-CPO-2007-2000636. Any opinions, findings and conclusions or recommendations expressed in this material are those of the authors and do not necessarily reflect the views of NSF, EPA or NOAA. R. Hamme was supported by a Gary Comer Abrupt Climate Change Fellowship.

\section{References}

Anderson, L. A. 1995. On the hydrogen and oxygen content of marine phytoplankton. Deep-Sea Res. I 42, 1675-1680.

Battle, M., Fletcher, S. M., Bender, M. L., Keeling, R. F., Manning, A. C., Gruber, N., Tans, P. P., Hendricks, M. B., Ho, D. T., Simonds, C., Mika, R. and Paplawsky, W. 2006. Atmospheric potential oxygen: New observations and their implications for some atmospheric and oceanic models. Global Biogeochem. Cycles 20, GB1010, doi:10.1029/2005GB002534.

Behrenfeld, M. J. and Falkowski, P. G. 1997. Photosynthetic rates derived from satellite-based chlorophyll concentration. Limnol. Oceanogr. $\mathbf{4 2}$, $1-20$.

Behrenfeld, M. J., O’Malley, R. T., Siegel, D. A., McClain, C. R., Sarmiento, J. L., Feldman, G. C., Milligan, A. J., Falkowski, P. G., Letelier, R. M. and Boss, E. S. 2006. Climate-driven trends in contemporary ocean productivity. Nature 444, 752-755.

Bender, M. L., Battle, M. and Keeling, R. F. 1998. The $\mathrm{O}_{2}$ balance of the atmosphere: A tool for studying the fate of fossil-fuel $\mathrm{CO}_{2}$. Annи. Rev. Energy Envion. 23, 207-223.

Bender, M. L., Ho, D. T., Hendricks, M. B., Mika, R., Battle, M. O., Tans, P. P., Conway, T. J., Stutevant, B. and Cassar, N. 2005. Atmospheric $\mathrm{O}_{2} / \mathrm{N}_{2}$ changes 1993-2002: Implications for the partitioning of fossil fuel $\mathrm{CO}_{2}$ sequestration. Global Biogeochem. Cycles 19, GB4017, doi:10.1029/2004GB002410.

Bopp, L., Le Quéré, C., Heimann, M., Manning, A. C. and Monfray, P. 2002. Climate-induced oxygen fluxes: Implications for the contemporary carbon budget. Global Biogeochem. Cycles 16, doi:10.1029/2001GB001445.

Deutsch, C., Emerson, S. and Thompson, L. 2006. Physical-biological interactions in North Pacific oxygen variability. J. Geophys. Res. 1111, C09S90, doi:10.1029/2005JC003179.

Ebisuzaki, W. 1997. A method to estimate the statistical significance of a correlation when the data are serially correlated. J. Climate $\mathbf{1 0}$, 2147-2153.

Emerson, S., Mecking, S. and Abell, J. 2001. The biological pump in the subtropical North Pacific Ocean: Nutrient sources, Redfield ratios, and recent changes. Global Biogeochem. Cycles 15, 535-554.

Friedrich, T., Oschlies, A. and Eden, C. 2006. Role of wind stress and heat fluxes in interannual-to-decadal variability of air-sea $\mathrm{CO}_{2}$ and $\mathrm{O}_{2}$ fluxes in the North Atlantic. Geophys. Res. Lett. 33, L21S04, doi:10.1029/2006GL026538.

Gruber, N., Gloor, M., Fan, S.-M. and Sarmiento, J. L. 2001. Air-sea flux of oxygen estimated from bulk data: Implications for the marine and atmospheric oxygen cycles. Global Biogeochem. Cycles 15, 783803.

Johnson, G. C. and Gruber, N. 2007. Decadal water mass variations along $20^{\circ} \mathrm{W}$ in the Northeastern Atlantic Ocean. Prog. Oceanogr. 73, 277-295.

Kalnay, E. and Co-authors. 1996. The NCEP/NCAR 40-year Reanalysis Project. Bull. Amer. Meteor. Soc. 77, 437-471.

Kawabata, H., Narita, H., Harada, K., Tsunogai, S. and Kusakabe, M. 2003. Air-sea gas transfer velocity in stormy winter estimated from radon deficiency. J. Oceanogr. 59, 651-661.

Keeling, R. F. 1988. Development of an Interferometric Oxygen Analyzer for Precise Measurement of the Atmospheric $\mathrm{O}_{2}$ Mole Fraction, $\mathrm{PhD}$ Thesis, Harvard University, Cambridge, Mass.

Keeling, R. F. and Garcia, H. 2002. The change in oceanic $\mathrm{O}_{2}$ inventory associated with recent global warming. Proc. Natl. Acad. Sci. USA 99, 7848-7853.

Keeling, C. D. and Revelle, R. 1985. Effects of El-Niño Southern Oscillation on the atmospheric content of carbon-dioxide. Meteoritics 20, 437-450.

Keeling, R. F. and Severinghaus, J. P. 2000. Atmospheric oxygen and the carbon cycle. In: The Carbon Cycle (eds T. M. L. Wigley, and D. S. Schimel). Cambridge University Press, Cambridge, 134-140.

Keeling, C. D., Piper, S. C., Robert, B., Wahlen, B. M., Whorf, T. P., Heimann, M. and Meijer, H. A. 2005. Atmospheric $\mathrm{CO}_{2}$ and ${ }^{13} \mathrm{CO}_{2}$ exchange with the terrestrial biosphere and oceans from 1978 to 2000 : Observations and carbon cycle interpretations. In: A History of Atmospheric $\mathrm{CO}_{2}$ and its Effects on Plants, Animals, and Ecosystems (eds J. R. Ehleringer, T. E. Cerling, and M. D. Dearing). Springer Science, New York, NY, 83-113.

Keeling, R. F., Manning, A. C., McEvoy, E. M. and Shertz, S. R. 1998a. Methods for measuring changes in atmospheric $\mathrm{O}_{2}$ concentration and their application in southern hemisphere air. J. Geophys. Res. 103, 3381-3397.

Keeling, R. F., Stephens, B. B., Najjar, R. G., Doney, S. C., Archer, D. and Heimann, M. 1998b. Seasonal variations in the atmospheric $\mathrm{O}_{2} / \mathrm{N}_{2}$ ratio in relation to the kinetics of air-sea gas exchange. Global Biogeochem. Cycles 12, 141-163.

Keeling, R. F., Manning, A. C., Paplawsky, W. J. and Cox, A. C. 2007. On the long-term stability of reference gases for atmospheric $\mathrm{O}_{2} / \mathrm{N}_{2}$ and $\mathrm{CO}_{2}$ measurements. Tellus 59B, 3-14. 
Keeling, R. F., Najjar, R. P., Bender, M. L. and Tans, P. P. 1993. What atmospheric oxygen measurements can tell us about the global carbon cycle. Global Biogeochem. Cycles 7, 37-67.

Keeling, R. F., Piper, S. C. and Heimann, M. 1996. Global and hemispheric $\mathrm{CO}_{2}$ sinks deduced from changes in atmospheric $\mathrm{O}_{2}$ concentration. Nature 381, 218-221.

Lazier, J., Hendry, R., Clarke, A., Yashayaev, I. and Rhines, P. 2002. Convection and restratification in the Labrador Sea, 1999-2000. Deep-Sea Res. I 49, 1819-1835.

Le Quéré, C., Rödenbeck, C., Buitenhuis, E. T., Conway, T. J., Langenfelds, R., Gomez, A., Labuschagne, C., Ramonet, M., Nakazawa, T., Metzl, N., Gillett, N. and Heimann, M. 2007. Saturation of the Southern Ocean $\mathrm{CO}_{2}$ sink due to recent climate change. Science 316, 1735-1738, doi:10.1126/science.1136188.

Levitus, S. ed. 2005. World Ocean Atlas, NOAA Atlas NESDIS 61, U.S. Government Printing Office, Washington, DC .

Levitus, S., Antonov, J. and Boyer, T. 2005. Warming of the world ocean, 1955-2003. Geophys. Res. Lett. 32, L02604, doi:10.1029/2004GL021592.

Manning, A. C. 2001. Temporal Variability of Atmospheric Oxygen from both Continuous Measurements and a Flask Sampling Network: Tools for Studying the Global Carbon Cycle. PhD Thesis, University of California, San Diego.

Manning, A. C. and Keeling, R. F. 2006. Global oceanic and land biotic carbon sinks from the Scripps atmospheric oxygen flask sampling network. Tellus 58B, 95-116.

Marland, G., Boden, T. A. and Andres, R. J. 2007. Global, regional, and national $\mathrm{CO}_{2}$ emissions. In: Trends: A Compendium of Data on Global Change, Carbon Dioxide Information Analysis Center, Oak Ridge National Laboratory, U.S. Department of Energy, Oak Ridge, Tenn.

McKinley, G. A., Follows, M. J., Marshall, J. and Fan, S.-M. 2003. Interannual variability of air-sea $\mathrm{O}_{2}$ fluxes and the determination of $\mathrm{CO}_{2}$ sinks using atmospheric $\mathrm{O}_{2} / \mathrm{N}_{2}$. Geophys. Res. Lett. 30, 1101, doi:10.1029/2002GL016044.

Naegler, T., Ciais, P., Orr, J. C., Aumont, O. and Rödenbeck, C. 2007. On evaluating ocean models with atmospheric potential oxygen. Tellus 59B, 138-156.

Nevison, C. D., Mahowald, N. M., Doney, S. C., Lima, I. D. and Cassar, N. 2008. Impact of variable air-sea $\mathrm{O}_{2}$ and $\mathrm{CO}_{2}$ fluxes on atmospheric potential oxygen (APO) and land-ocean carbon sink partitioning. Biogeosciences, 5, 875-889.

Ono, T., Midorikawa, T., Watanabe, Y. W., Tadokoro, K. and Saino, T. 2001. Temporal increases of phosphate and apparent oxygen utilization in the subsurface waters of western subarctic Pacific from 1968 to 1998. Geophys. Res. Lett. 28, 3285-3288.

Patra, P. K., Ishizawa, M., Maksyutov, S., Nakazawa, T. and Inoue, G. 2005. Role of biomass burning and climate anomalies for land-atmosphere carbon fluxes based on inverse modeling of atmospheric $\mathrm{CO}_{2}$. Global Biogeochem. Cycles 19, GB3005, doi:10.1029/2004GB002258.

Plattner, G. K., Joos, F. and Stocker, T. F. 2002. Revision of the global carbon budget due to changing air-sea oxygen fluxes. Global Biogeochem. Cycles 16, 1096.

Qiu, B. and Chen, S. 2006. Decadal variability in the formation of the North Pacific Subtropical Mode Water: Oceanic versus atmospheric control. J. Phys. Oceanogr. 36, 1365-1380.
Rayner, P. J., Enting, I. G., Francey, R. J. and Langenfelds, R. 1999. Reconstructing the recent carbon cycle from atmospheric $\mathrm{CO}_{2}, \delta^{13} \mathrm{C}$ and $\mathrm{O}_{2} / \mathrm{N}_{2}$ observations. Tellus 51B, 213-232.

Rödenbeck, C., Houweling, S., Gloor, M. and Heimann, M. 2003. $\mathrm{CO}_{2}$ flux history 1982-2001 inferred from atmospheric data using a global inversion of atmospheric transport. Atmos. Chem. Phys. 3, 1919-1964.

Rödenbeck, C., Quéré, C. L., Heimann, M. and Keeling, R. 2008. Interannual variability in oceanic biogeochemical processes inferred by inversion of atmospheric $\mathrm{O}_{2} / \mathrm{N}_{2}$ and $\mathrm{CO}_{2}$ data. Tellus $\mathbf{6 0 B}$, DOI: $10.1111 / \mathrm{j} .1600-0889.2008 .00375 . x$.

Ronski, S. and Budéus, G. 2005. Time series of winter convection in the Greenland Sea. J. Geophys. Res. 110, C04015, doi:10.1029/2004JC002318.

Schuster, U. and Watson, A. J. 2006. A variable and decreasing sink for atmospheric $\mathrm{CO}_{2}$ in the North Atlantic. J. Geophys. Res. 112, C11006, doi:10.1029/2006JC003941.

Severinghaus, J. P. 1995. Studies of the Terrestrial $\mathrm{O}_{2}$ and Carbon Cycles in Sand Dune Gases and in Biosphere 2. PhD Thesis, Columbia Univ.

Shcherbina, A. L., Talley, L. D. and Rudnick, D. L. 2004. Dense water formation on the northwestern shelf of the Okhotsk Sea: 1. Direct observations of brine rejection. J. Geophys. Res. 109, C09S08, doi:10.1029/2003JC002196.

Stephens, B. B., Keeling, R. F., Heimann, M., Six, K. D., Murnana, R. and Caldeira, K. 1998. Testing global ocean carbon cycle models using measurements of atmospheric $\mathrm{O}_{2}$ and $\mathrm{CO}_{2}$ concentration. Global Biogeochem. Cycles 12, 213-230.

Talley, L. D. 1997. North Pacific Intermediate Water transports in the mixed water region. J. Phys. Oceanogr. 27, 1795-1803.

Talley, L. D., Lobanov, V., Ponomarev, V., Salyuk, A., Tishchenko, P., Zhabin, I. and Riser, S. 2003. Deep convection and brine rejection in the Japan Sea. Geophys. Res. Lett. 30, 1159, doi:10.1029/2002GL016451.

Thompson, D. W. J. and Wallace, J. M. 2001. Regional climate impacts of the Northern Hemisphere annular mode. Science 293, 8589.

Tohjima, Y., Mukai, H., Machida, T., Nojiri, Y. and Gloor, M. 2005. First measurements of the latitudinal atmospheric $\mathrm{O}_{2}$ and $\mathrm{CO}_{2}$ distributions across the western Pacific. Geophys. Res. Lett., (17), L17805, doi:10.1029/2005/GL023311.

Tohjima, Y., Mukai, H., Nojiri, Y., Yamagishi, H. and Machida, T. 2008. Atmospheric $\mathrm{O}_{2} / \mathrm{N}_{2}$ measurements at two Japanese sites: Estimation of global oceanic and land biotic carbon sinks and analysis of the variation in atmospheric potential oxygen (APO). Tellus 60B, 213225.

Verdy, A., Dutkiewicz, S., Follows, M. J., Marshall, J. and Czaja, A. 2007. Carbon dioxide and oxygen fluxes in the Southern Ocean: Mechanisms of interannual variability. Global Biogeochem. Cycles 21, GB2020, doi:10.1029/2006GB002916.

Willis, J. K., Lyman, J. M., Johnson, G. C. and Gilson, J. 2007. Correction to "Recent cooling of the upper ocean". Geophys. Res. Lett. 34, L16601, doi:10.1029/2007GL030323.

Willis, J. K., Roemmich, D. and Cornuelle, B. 2004. Interannual variability in upper ocean heat content, temperature and thermosteric expansion on global scales. J. Geophys. Res. 109, C12036, doi:10.1029/2003JC002260.

Yashayaev, I. 2007. Hydrographic changes in the Labrador Sea, 19602005. Prog. Oceanogr. 73, 242-276. 